\title{
La costumbre en el Derecho histórico de Mallorca
}

\section{The costum in Majorcan Historical law}

\author{
Antonio PLANAS ROSSELLÓ \\ Profesor Titular de Historia del Derecho y de las Instituciones \\ Departamento de Derecho Público \\ Universitat de les Illes Balears \\ antonio.planas@uib.es
}

Recibido: 6 de julio de 2015

Aceptado: 2 de septiembre de 2015

\section{RESUMEN}

El presente artículo se centra en el estudio del papel de la costumbre en el derecho de Mallorca a partir de la conquista de Jaime I de 1229. Tras analizar los mecanismos a través de los cuales se llegó a configurar un derecho consuetudinario unitario, a pesar de la diversidad de procedencias de los repobladores catalanes de la isla, se estudia el impacto de la recepción del Ius Commune sobre las instituciones consuetudinarias y las repercusiones de la redacción oficial de las costumbres y los usos judiciales. Por último, se lleva a cabo un estudio específico sobre el papel de la costumbre en materia penal.

PALABRAS CLAVE: Costumbre, Ius Commune, estilo judicial, Arnau d'Erill, Mallorca.

\begin{abstract}
This article is focused on the study of the role of custom in Majorcan law after the conquest of James I in 1229. After analyzing the mechanisms through which customary law came to uniformity, despite the diverse origins of Catalan settlers of the island, the impact of reception the Ius Commune on customary institutions and the impact of the official wording of the customs and judicial practice are studied. Finally, an specific study on the role of custom in criminal matters is developed.
\end{abstract}

KEYWORDS: Costum, Ius Commune, judicial style, Arnau d'Erill, Majorca.

\section{RÉSUMÉ}

Le présent article se centre sur l'étude du rôle de la coutume dans le droit de Majorque après la conquête de Jacques I en 1229. Après l'analyse des mécanismes par lesquels on arrive à configurer un droit coutumier uniforme, malgré la diversité des origines des colons catalans de l'île, on y va étudier l'impact de la réception du Ius commune sur les institutions coutumières et les répercussions de la rédaction officielle des coutumes et des usages judiciaires. Pour finir, on y mène à bout une étude spécifique sur le rôle de la coutume en matière pénale.

MOTS CLÉ : Coutume, Ius Commune, style judiciaire, Arnau d'Erill, Majorque.

SUMARIO: 1. La formación de la costumbre en el reino de Mallorca 2. La costumbre tras la recepción oficial del Ius Commune. 3. La redacción de las costumbres y estilos judiciales. 4. La costumbre en el ámbito penal. 


\section{La formación de la costumbre en el reino de Mallorca}

La conquista cristiana de Mallorca se produjo en 1229, en una etapa avanzada del tránsito entre dos culturas jurídicas, la altomedieval y la bajomedieval o, según la característica formulación de Paolo Grossi, la época en que el derecho nace en el taller de la praxis y la época en que se crea en el taller sapiencial. ${ }^{1}$ Mientras que en la primera el derecho tuvo una base esencialmente consuetudinaria y el poder público apenas intervino en la creación de las normas, en la segunda el sistema jurídico se hizo más complejo como consecuencia del renacimiento del poder legislativo de los monarcas y la difusión del antiguo derecho romano justinianeo, recuperado y reelaborado por los juristas universitarios.

Los sistemas jurídicos de la mayor parte de los reinos cristianos se desarrollaron a partir de la costumbre altomedieval. Era el "antiguo y buen Derecho", según la conocida expresión de Fritz Kern. ${ }^{2}$ Pero, poco a poco, a lo largo de la Baja Edad Media, el orden jurídico se fue adaptando a las necesidades de una sociedad cambiante a través de una legislación regia cada vez más nutrida, y de una difusión del Ius Commune romano-canónico cada vez más intensa. Este fue un fenómeno común a todos los reinos del entorno mediterráneo. Las diferencias residieron en el distinto papel que se asignó a esos tres elementos -costumbre, legislación regia y Ius Commune- en cada uno de ellos.

El papel de la costumbre en el sistema jurídico de Mallorca ha sido controvertido. A juicio de los profesores Lalinde Abadía ${ }^{3}$ y Piña Homs ${ }^{4}$ la costumbre constituyó la base normativa del ordenamiento jurídico de Mallorca, como en los restantes territorios de la Corona de Aragón. Sin embargo, tratándose de un reino nacido a partir de la conquista de Jaime I, la naturaleza de la costumbre mallorquina no puede equipararse con la de otros territorios peninsulares en los que existió una continuidad jurídica en el tiempo.

Como es sabido, no hubo en Mallorca una comunidad de mozárabes de origen autóctono que pudiese conservar un derecho cristiano anterior a la conquista. Mikel de Epalza considera que en aquel momento pudieron existir neo-mozárabes, esto es, una minoría de cristianos instalados en la isla durante la época islámica por razones diplomáticas, militares o comerciales, ${ }^{5}$ mientras que Alvaro Santamaría apunta la po-

\footnotetext{
${ }^{1}$ P. Grossi, El orden jurídico medieval, Madrid, 1996.

${ }^{2}$ F. Kern, Derecho y Constitución en la Edad Media, Ed. de F. Martínez Martínez, Valencia, 2013. Vid. así mismo M. García Pelayo, La idea medieval del derecho, Caracas, 2013.

${ }^{3}$ J. Lalinde Abadía, "La costumbre en los territorios ibéricos de la Corona de Aragón", Recueils de la Société Jean Bodin pour l'histoire comparative des institutions, LII, 1990, pp. 181-192.

${ }^{4}$ R. Piña Homs, El Derecho histórico del Reino de Mallorca, Palma, 1993, pp. 72-77.

${ }^{5}$ M. de Epalza, "Los cristianos en las Baleares musulmanas", Les illes orientals d'Al-Andalus, Palma, 1987, pp. 133-143.
} 
sibilidad de que hubiese en la ciudad una reducida comunidad de cristianos - los llamados arrom - con una permanencia más prolongada, aunque en todo caso posterior a la cruzada pisano-catalana de 1114-1115, y carente de una organización institucionalizada. ${ }^{6}$ Por ello, no es posible buscar el origen de las instituciones civiles mallorquinas en una pervivencia consuetudinaria del derecho romano desde la Antigüedad, ni mucho menos en la supuesta prolongación de costumbres germánicas arraigadas tras la efímera ocupación vándala del archipiélago. En este sentido, es preciso rechazar las hipótesis planteadas por Pascual González en una monografía publicada en 1951, cuando los conocimientos sobre el pasado histórico de Mallorca no habían experimentado los avances que se han producido en las últimas décadas. ${ }^{7} \mathrm{El}$ merecido prestigio de este autor, que contribuyó tan eficazmente a la conservación del derecho propio de Mallorca antes de su compilación, ha hecho que esas hipótesis, que en su obra tienen un carácter meramente accidental, se hayan reproducido por algunos civilistas hasta tiempos muy recientes, ${ }^{8}$ cuando los avances historiográficos ya no permiten sustentarlas.

$\mathrm{Al}$ contrario que en la mayor parte de los territorios peninsulares de la Corona de Aragón, la costumbre mallorquina se desarrolló a partir de la conquista de Jaime I, como aportación de los repobladores venidos de diversos lugares del continente. Por ese motivo el profesor Aquilino Iglesia afirma que, en realidad, desde el mismo instante de su conquista, el derecho general de Mallorca fue el Ius Commune romanocanónico, matizado por un derecho de creación regia. ${ }^{9}$ El autor desecha la costumbre como base del sistema jurídico con dos argumentos:

a) Por una parte, entiende que la base del sistema no puede tratarse de la costumbre de los repobladores, puesto que estos procedían de diferentes lugares y carecían de un derecho consuetudinario común.

b) Por otra, considera impensable que incluso en un reino de dimensiones reducidas como el de Mallorca se pudiera formar un nuevo derecho consuetudinario que diese respuesta a una sociedad tan activa desde el punto de vista social, económico, político y cultural, como la que se estaba formando.

No cabe duda de que las escasas disposiciones regias dictadas a lo largo del siglo XIII no conformaron un ordenamiento jurídico completo, sino que fueron reglas fragmentarias que excepcionaban un régimen general. Sin embargo, en la época de la conquista la difusión del derecho romano-canónico no había alcanzado su plenitud y, por tanto, no pudo constituir la única base de ese régimen. En realidad, el Ius Com-

\footnotetext{
${ }^{6}$ A. Santamaría Arández, Ejecutoria del reino de Mallorca. 1230-1343, Palma, 1990, p. 213.

${ }^{7}$ L. Pascual González, Derecho civil de Mallorca, Palma, 1951.

${ }^{8}$ A. Martínez Cañellas, "Sobre el derecho consuetudinario balear como fuente y como tradición jurídica", Boletín de la Academia de Jurisprudencia y Legislación de las Illes Balears, 10 (2009), pp. 31-84; F. Bauzá Martorell, "Tradición jurídica civil balear del derecho de toma de agua. Vigencia de las antiguas costumbres", BAJLIB, 12 (2012), pp. 103-164.
}

${ }^{9}$ A. Iglesia Ferreirós, La creación de Derecho, Madrid, 1996, II, p. 133. 
mune, el derecho de creación regia y el derecho consuetudinario fueron diferentes estratos jurídicos que se superpusieron, y a veces llegaron a confundirse.

Los repobladores del reino de Mallorca procedían en su inmensa mayoría de diferentes regiones de Cataluña que, en esa etapa de dispersión normativa, poseían diferentes instituciones consuetudinarias. Sin lugar a dudas, ese factor dificultaba la conformación de un régimen general basado en la costumbre. No disponemos de manifestaciones claras acerca de ese problema en la documentación coetánea de la isla de Mallorca, pero contamos con un interesante testimonio de la de Ibiza, donde la situación era análoga: el 13 de julio de 1264, Guillem de Montgrí, como señor de la isla, fijó un plazo de diez años para la prescripción de los inmuebles, alegando que lo hacía com de les noves adquisicions de les terres, per la diversitat de las costumes dels habitants de diversos lochs e regions venguts en aquellas, moltes questions se acostumen neixer. ${ }^{10}$ Ante esa diversidad de costumbres, Montgrí estableció una solución unitaria, imponiendo un plazo que, significativamente, era el propio del derecho romano.

Desde el siglo XIII las diversas disposiciones que relacionan las fuentes del derecho mallorquín, especialmente los textos de las confirmaciones de los privilegios otorgadas por los monarcas, mencionan siempre las consuetudines insulae. Sin embargo, se debe tener en cuenta que en el ámbito catalán, los términos 'consuetudo' y 'costum' equivalen a lo que en Castilla es 'fuero'. Así, los libros de Costums de Gerona, Lérida, Tortosa o Valencia recogen un derecho que no es estrictamente consuetudinario, sino que puede proceder, entre otras fuentes, de privilegios y ordenanzas reales o municipales. ${ }^{11}$ Ese uso amplio del término 'costum' se encuentra asimismo en Mallorca. Por ejemplo, una provisión regia de 1269 se refiere a la regulación del crimen enorme establecida en la carta de población diciendo in vestris consuetudinibus sive cartis contentis, ${ }^{12}$ y en 1340 los registros del Real Patrimonio se refieren al códice de privilegios y franquezas de Mallorca que poseía el rey Jaime III como $\mathrm{Li}$ brum consuetudinum Maiorice. ${ }^{13}$ Como ha observado Paola Miceli, en los siglos XIII y XIV existió una creciente tendencia a ubicar en el mismo nivel que la palabra 'consuetudo' a las libertades o privilegios que poseía una comunidad. La utilización constante de los distintos términos (libertades, privilegios, franquezas, costumbres) en calidad de sinónimos, revela que en este período la costumbre se había transformado en un signo de libertad y en una marca de identidad. ${ }^{14}$

\footnotetext{
${ }^{10}$ Arxiu Municipal d'EIvissa, Llibre de la cadena, f. 43.

${ }^{11}$ J. Lalinde Abadía, Iniciación histórica al Derecho español, Barcelona, 1970, pp. 86-87. J. Beneyto, “Observaciones sobre el sentido de vocablo «Costum»", Costums de Tortosa. Estudis, Tortosa, 1979, pp. 9-13.

${ }^{12}$ Archivo del Reino de Mallorca, Llibre de privilegis dels Reis, f. 40.

${ }^{13}$ C. A. Willemsen, "Algunes notícies sobre un còdex de les franquícies de Mallorca a l'Arxiu de la Corona d'Aragó", Bolleti de la Societat Arqueològica Luliana, XXII, 1928-1929, p. 385.

${ }^{14} \mathrm{P}$. Miceli, "El derecho consuetudinario en Castilla. Una crítica a la matriz romántica de las interpre-
} 
En todo caso, mediante privilegio de 5 de enero de 1286, Alfonso III ratificó los buenos usos y las buenas costumbres de Mallorca, con las siguientes palabras: "Encara us atorgam bons usos e bones costumes axi com d'aquells havets usats". ${ }^{15} \mathrm{En}$ esta ocasión el monarca quiso confirmar de forma inequívoca la validez del derecho consuetudinario propiamente dicho. $\mathrm{Y}$ de hecho, esta disposición regia fue invocada en lo sucesivo como su principal fundamento. ${ }^{16}$

Ahora bien, dado el diferente origen de los repobladores es necesario plantearse cómo se configuraron esas costumbres.

1. En primer lugar, el intensísimo tráfico jurídico generado por el reparto de tierras y la transmisión, administración y explotación de los bienes adquiridos a raíz de la conquista, aceleraron la aparición de modalidades genuinas respecto a determinados negocios jurídicos. Así, ya Álvaro Santamaría detectó en la documentación de la década de 1240 alusiones a una consuetudo Maioricarum, que se aplica a la obligación de restitución en los contratos de comanda de ganado o respecto al saneamiento por vicios ocultos en las compraventas de esclavos. ${ }^{17}$

2. En segundo lugar, a pesar de que los repobladores procedían en su inmensa mayoría de distintas localidades catalanas dotadas de costumbres diferenciadas, existía un acervo jurídico común que afectaba a importantes instituciones. La existencia de ese fondo jurídico generalizado se debía a causas diversas, entre las que destaca la pervivencia por vía consuetudinaria de determinados preceptos del Liber Iudiciorum visigótico y, sobre todo, el importante influjo del derecho común romano-canónico, que desde el último cuarto del siglo XII se había se había dejado sentir por todo el territorio catalán. Por ejemplo, la tenencia de tierras mediante el sistema de acapte o establiment, muy extendido en Cataluña, de donde se importó a Mallorca, se había ido asimilando paulatinamente a la enfiteusis romana, aunque ese término no se generalizase hasta mucho más tarde. ${ }^{18}$

Las únicas costumbres a las que la documentación mallorquina del siglo XIII hace remisiones explícitas son las de Barcelona. A ellas se someten las donaciones en feudo otorgadas por el monarca o los magnates catalanes en los primeros decenios posteriores a la conquista, y también muchos de los esponsalicios otorgados en esas fechas.

taciones sobre la costumbre", Hispania, LXIII/1, 2003, p. 17; P. Miceli, Derecho consuetudinario y memoria. Práctica jurídica y costumbre en Castilla y León (siglos XI-XIV), Madrid, 2012, p. 104.

${ }^{15}$ ARM, Llibre d'en Sant Pere, f. 139v.

${ }^{16}$ En algunos pleitos de principios del siglo XIV en los que una de las partes alega a su favor una institución consuetudinaria, se invoca la disposición de Alfonso III para fundamentar la obligatoriedad de su observancia (Vid. ARM, Suplicacions, 1). Por otra parte, en uno de los códices de franquezas del reino de Mallorca del siglo XIV se reproduce esta norma previamente a la recopilación de costumbres y estilos curiales de Mallorca de Arnau d'Erill (1344), como fundamento para la aplicación de los usos y costumbres (ARM, Códice 90, f. 31v).

${ }^{17}$ A. Santamaría Arández, Ejecutoria del Reino de Mallorca (1230-1343), Palma, 1990, p. 605.

${ }^{18}$ J. M. Pons i Guri, "Entre l'emfiteusi i el feudalisme (Els reculls de dret gironins)", Estudi General, 5-6, 1985-1986, p. 415. 
3. En tercer lugar, durante el siglo XIII convivieron diferentes instituciones consuetudinarias que se aplicaban en virtud de la autonomía de la voluntad de los pobladores. Esta realidad queda patente en los documentos de aplicación del derecho de la época. Así vemos convivir, con idéntica validez, diversas modalidades de actos o negocios jurídicos mediante los que se configuran importantes aspectos de la vida social. Esta realidad se observa también en la Cataluña de la época donde, como señala Lalinde, existía un "indecisionismo normativo" motivado por la convivencia de modelos de origen visigótico con otros procedentes del Ius Commune, que iniciaba una tímida expansión. ${ }^{19}$

Tal indecisión era fuente de inseguridad jurídica y, por ello, hasta finales del siglo XIII muchos instrumentos mallorquines incluyeron una expresiva renuncia accioni et benefficio legis gotiche et Usaticorum Barchinona, et omni jure tam promulgato quam promulgando, publico et privato, canonico et civili, tam spetiali quam generali, divino et humano, scripto et non scripto sive consuetudinario. ${ }^{20}$ Ese tipo de renuncias, bien documentadas asimismo en Cataluña, respondían al deseo de aportar seguridad jurídica, afianzando la voluntad de las partes negociales frente a las sutilezas de derecho que podían invocar los abogados, basándose en los remedios que los diferentes sistemas jurídicos del momento podían ofrecer. ${ }^{21}$

La diversidad consuetudinaria se puede apreciar de forma especialmente ilustrativa en el campo de los regímenes económicos matrimoniales y en el de las modalidades testamentarias.

Respecto a los primeros, como ha demostrado Carme Coll Font, en los años posteriores a la conquista se documentan distintos sistemas que están claramente relacionados con el lugar de origen de los cónyuges. Así, entre 1239 y 1243 los pobladores procedentes de lo que hoy son las comarcas de Osona, la Selva, Gironès y Baix Empordà utilizaron preferentemente el régimen de agermanament $\mathrm{o}$ mig per mig, aunque también se acudió al esponsalicio y aixovar, mientras que los oriundos de las comarcas centrales de Cataluña utilizaron normalmente el esponsalicio, sin que haya presencia alguna del mig per mig o el agermanament. ${ }^{22}$ Junto a ellos se encuentran algunos casos de asociación de compras o mejoras, que según Lalinde son característicos del Campo de Tarragona y el Penedés. Es muy significativo que en este periodo el régimen dotal, de tradición romana, tuviese un carácter minoritario. Sin embargo, desde finales del siglo XIII fue ganando terreno aceleradamente, ${ }^{23}$ hasta

\footnotetext{
${ }^{19}$ J. Lalinde Abadía, "Los pactos matrimoniales catalanes", Anuario de Historia del Derecho Español, XXXIII, 1963, p. 171.

${ }^{20}$ ARM, ECR 349, f. 4.

${ }^{21}$ A. Iglesia Ferreirós, La creación de Derecho, II, pp. 118-119.

${ }^{22}$ M. C. Coll Font, El Llibre Manual de Pere Romeu, notari públic de Mallorca (1239-1243), Tesis Doctoral Inédita, Universitat de les Illes Balears, 2012, I, pp. 161-163.

${ }^{23}$ Plàcid Pérez Pastor tras analizar detenidamente la documentación notarial de la villa de Soller entre los años 1289 y 1325 ha podido determinar que hasta el año 1300 el régimen de agermanaments se da
} 
llegar a sustituir completamente a aquellas modalidades consuetudinarias en los primeros años del siglo XV. En todo caso, la dote quedó acompañada por un elemento de origen indudablemente consuetudinario, el escreix o incremento dotal que otorgaba el marido a la mujer. ${ }^{24}$ Aunque la institución pudo tener su origen en la donación propter nuptias romana, el hecho de que solamente se otorgase a las mujeres vírgenes - propter corporis vestri virginitatem, se señala en los instrumentos de constitución ${ }^{25}$ parece entroncarla con una tradición germánica aportada sin duda por los repobladores catalanes.

Respecto a los segundos, durante el siglo XIII, junto al testamento nuncupativo secreto, manifestado ante notario, se acudía muchas veces al llamado testamento sacramental o, más bien, de adveración sacramental. Se trataba de un testamento abierto o verbal otorgado por el causante ante varios testigos sin intervención notarial que, tras su muerte, debía ser adverado bajo juramento ante el baile y diversos testigos en el altar de Santa Eulalia de la ciudad de Mallorca o en algunas iglesias de las villas foráneas. Esta modalidad testamentaria, que respondía a una vieja tradición catalana derivada del Liber Iudiciorum, ${ }^{26}$ tras un lento declive acabó por desaparecer en los primeros decenios del siglo XIV. ${ }^{27}$

4. En cuarto lugar, la convivencia en un espacio insular bien delimitado hizo que se generalizasen algunas costumbres originariamente particulares, por su mejor adaptación a las circunstancias del momento. Así, determinadas modalidades consuetudinarias desaparecieron por su progresivo desuso, siendo sustituidas por aquellas que resultaron más adecuadas o, en su caso, por las soluciones provenientes del Ius Commune.

Uno de los medios que sin duda contribuyeron a la fijación de las costumbres en las décadas posteriores a la conquista debió ser la participación de prohombres legos en la formación de las sentencias, de acuerdo con lo previsto por la carta de población de $1230 .{ }^{28}$ Pero además, se debe considerar que aunque las costumbres sean, en principio,

en un $46{ }^{\prime} 2 \%$ frente al $53{ }^{\prime} 8 \%$ de instrumentos dotales. Tras unos años de falta de datos, entre 1317 y 1325 la proporción pasa a un 9'1\% de agermanaments y un 90'9\% de regímenes dotales (P. Pérez Pastor, "Amor i economia a la Part Forana de Mallorca entre la fraternitat de béns i les esposalles (1288-1325)", Jaume II, Sanç I: dues actituds un mateix projecte, Palma, 2011, pp. 209-230).

${ }^{24}$ La cuantía del escreix, que en principio era variable, fue fijada legalmente por Sancho I, a petición de los jurados del reino, mediante privilegio de 8 de julio de 1316, disponiendo que no pudiera superar una cuarta parte del valor de la aportación femenina (ARM, Llibre de Sant Pere, f. 182v. Pub. J. Salvá, Derecho de familia en Mallorca, Palma, 1918, p. 131).

${ }^{25}$ L. Zaforteza; A. Mut Calafell, M. Oliver Moragues, Tratados de Notaría en el reino de Mallorca, Guadalajara, 1995, p. 452.

${ }^{26}$ A. M. Udina Abelló, "La adveración sacramental del testamento en la Cataluña altomedieval", $M e-$ dievalia, 12, 1995, pp. 51-64.

${ }^{27}$ El texto más reciente en que lo hallamos mencionado es una disposición de Jaime II de 9 de marzo de 1302 que prohíbe a los bailes de los magnates hacer publicar sacramentales y últimas voluntades (E. K. Aguiló, “Cartas reales. Rúbrica”, BSAL, XX, 1925, p. 265).

${ }^{28}$ A. Planas Rosselló, "La participación popular en la Administración de justicia del reino de Mallorca", AHDE, 66, 1996, pp. 151-180. 
un derecho no escrito, el siglo XIII es ya una época de cultura escrita y, en consecuencia, los actos y negocios jurídicos que se llevan a cabo en aplicación de las mismas, se documentan en instrumentos notariales. De esta manera se pudo imponer un elemento técnico, erudito, en la medida en que los notarios encauzaron la voluntad negocial de los particulares utilizando modelos y fórmulas procedentes, en muchos casos, del Derecho romano.

5. Por último, cuando la coexistencia de diferentes tradiciones jurídicas consuetudinarias podía dar lugar a conflictos, si la propia práctica no conseguía reducirlas a la unidad se producía una intervención del monarca, generalmente a instancias de los representantes regnícolas, para establecer una regla común. Entre otros ejemplos podemos citar la regulación legal de instituciones como la prescripción adquisitiva de los bienes inmuebles en $1251,{ }^{29} \mathrm{o}$ la adquisición del tesoro oculto en $1286,{ }^{30}$ en ambos casos de acuerdo con las reglas de derecho romano.

En otras ocasiones, los monarcas, a petición de los representantes del reino, suprimieron determinadas reglas consuetudinarias perfectamente asentadas, por considerarlas injustas o inadecuadas, sustituyendo los antiguos usos por una nueva regulación legal. Por ejemplo, hasta los primeros años del siglo XIV estuvo en vigor en Mallorca la institución de la goyda, que permitía a las viudas apropiarse de los frutos de la herencia de sus maridos hasta que les fuese reintegrada la dote y el esponsalicio. ${ }^{31}$ Mediante provisión de Sancho I de 11 de junio de 1316, esta institución consuetudinaria fue expresamente abolida, a petición de los síndicos del reino, para evitar los inconvenientes que suponía para los herederos, y sustituida por el derecho a que se les suministrase vestido y alimentos con cargo a los bienes del marido, durante el año siguiente a su fallecimiento. ${ }^{32}$ La nueva regulación, sin embargo, no fue una creación jurídica mallorquina. Se trataba de una conocida institución barcelonesa, ${ }^{33}$ el llamado any de plor, que Pedro IV extendería al conjunto de Cataluña mediante la constitución Hanc Nostra de $1351 .{ }^{34}$

\section{La costumbre tras la recepción oficial del Ius Commune}

El panorama descrito hasta ahora sufrió una transformación sustancial a raíz de la reforma de las franquezas de Mallorca impuesta por Jaime II el 30 de enero de 1300,

\footnotetext{
${ }^{29}$ Señala un plazo de prescripción de diez años continuos, cuando exista buena fe y justo título (ARM, Llibre de Privilegis dels Reis, f. 245).

${ }^{30}$ Privilegio de 5 de enero de 1286: Item concedimus vobis quod si forte aliqui invenerint tesaurum vel de cetero invenerint fiat de eo prout continetur in lege romana (Archivo de la Corona de Aragón, Real Cancillería, Alfonso III, Reg. 63, f. 24v).

${ }^{31}$ Hemos documentado la exigencia de estos frutos en concepto de goyda "secundum consuetudinem Maioricarum" en un pleito del año 1302 (ARM, Suplicacions 2, f. 299).

${ }^{32}$ J. Salvá, Derecho de familia..., pp. 159-160. Versión catalana en A. Planas Rosselló, Recopilación del Derecho de Mallorca de 1622, por los doctores Pere Joan Canet, Antoni Mesquida y Jordi Zaforteza, Palma, 1996, p. 198.

${ }^{33}$ Se halla recogida en los capítulos 5 y 6 del Recognoverunt Proceres.

${ }^{34}$ Constitucions y Altres Drets de Catalunya, V, III. 1.
} 
al inaugurar la segunda fase de su reinado. El monarca dispuso que todos los pleitos y causas se juzgasen según las costumbres de Mallorca: ervatis consuetudinibus et libertatibus Civitate et insule supradicte per nos nunc confirmatis seu concessis, en su defecto según los Usatges de Barcelona en los casos en los que correspondía hacerlo -que eran exclusivamente de carácter penal o feudal-, y en defecto de ambos illis consuetudinibus et Usaticis deficientibus, según el Ius Commune. ${ }^{35}$

A lo largo del siglo XIII, como hemos visto, el derecho romano había alcanzado una importante difusión de Mallorca, aunque de forma un tanto inadvertida. Como escribió Kern el derecho romano "es acogido ingenuamente por parte del derecho consuetudinario como si fuera una pieza de sí mismo, y hace estallar la cada vez más debilitada corteza de este Derecho, como si fuera una semilla madura" ${ }^{36}$ La disposición de Jaime II supuso la recepción oficial del derecho común en Mallorca y, en consecuencia, el estallido de esa semilla consuetudinaria se produjo de forma consciente y radical. Aunque en el texto se le atribuía el carácter de derecho supletorio, en la práctica constituyó desde entonces un elemento integrador que incluso modificó la naturaleza y eficacia de las restantes fuentes, especialmente de la costumbre, pues la sometió a unos estrictos requisitos que tendieron a reducir su vitalidad. Y es que allí donde se abre camino el Ius Commune, al que los juristas consideran como ratio scripta, inmediatamente se arroga una primacía casi absoluta y determina la interpretación de todas las demás fuentes.

Por este motivo, a partir de la recepción oficial, para que la costumbre fuese aplicada por los jueces, debía ser alegada y probada por la parte interesada. Los primeros pleitos cuyos autos se han conservado en los archivos mallorquines son los seguidos ante la curia del lugarteniente real en el año 1300. En algunos de ellos se alegan determinadas costumbres o usos judiciales de Mallorca, cuyo contenido y vigencia se prueba mediante testigos. Por ejemplo, se alegan usos como el de dar fianzas por las costas de las apelaciones iuxta consuetudinem curiae domini regis, ${ }^{37} \mathrm{o}$ la necesidad de que intervengan siete testigos para que el testamento sea válido. ${ }^{38}$ En uno de esos pleitos vemos oponerse dos distintas concepciones acerca del derecho consuetudinario. Para una de las partes, que invoca expresamente la citada confirmación de Alfonso III, las buenas costumbres confirmadas por el monarca son aquellas que son observadas de forma general por los habitantes de la isla, con la común convicción de su bondad (homines de terra ista tenebant usum et consuetudinem per bona et ipsam servabant per bona). Según esa concepción, el elemento que otorgaba validez a la costumbre era el consentimiento de todos (consensu omnium). En cambio, para la otra, siguiendo la doctrina del Ius commune, sólo pueden ser invocadas y denominarse propiamente cos-

\footnotetext{
${ }^{35}$ ARM, Llibre de jurisdiccions $i$ stils, ff. 43-44.

${ }^{36}$ F. Kern, Derecho y Constitución en la Edad Media, p. 131.

${ }^{37}$ ARM, Suplicacions 1, f. 52v.

${ }^{38}$ ARM, Suplicacions 1, f. 53.
} 
tumbres o usos, aquéllas que hayan sido obtenidas por lo menos dos veces en juicio contradictorio, y que reúnan otros requisitos determinados (non valet aliqua consuetudo nec dicere debet consuetudo nisi saltem bis fuerit per ea obtentum in contradictorio iuditio).$^{39}$ En aquel momento la opinión más seguida al respecto era la del canonista Enrico de Susa, cardenal de Ostia, para quien la costumbre consiste en aquel uso racional que se caracteriza por ser confirmado por el transcurso de un determinado espacio de tiempo; que no ha sido interrumpido por algún acto contrario; que se produce por un acto frecuente o inmemorial o a través de un juicio contradictorio; y que ha sido aprobado o confirmado por el uso común de aquellos que lo utilizan. ${ }^{40}$

Desde los primeros años del siglo XIV no cabe duda de que la costumbre se vio sometida a los requisitos restrictivos impuestos por el Ius commune. En los pleitos que hemos podido consultar, las partes que alegan costumbres aducen o bien que han sido obtenidas en juicio contradictorio o bien que se han venido practicando desde hace más de cuarenta años, lo que les confiere un carácter inmemorial. Respecto a este punto, en las glosas más antiguas sólo se hacía mención a la costumbre inmemorial, cuius non extat memoriae, que solía concretarse en una duración superior a los cuarenta años. ${ }^{41}$ En cambio, la canonística distinguía entre la costumbre praeter legem, que requería sólo un plazo de diez años, y la costumbre contra legem, que exigía el transcurso de cuarenta. ${ }^{42}$ Sin embargo no nos ha sido posible determinar cuál fue la doctrina que siguieron al respecto los tribunales de Mallorca, si es que llegaron a mantener una interpretación uniforme.

\section{La redacción de las costumbres y estilos judiciales}

Un nuevo paso de cara a la limitación de la costumbre como fuente del derecho tuvo lugar poco después de la reincorporación de Mallorca a la Corona de Aragón por Pedro IV. El 30 de julio de 1344, el gobernador Arnau d'Erill sancionó una colección oficial de derecho consuetudinario. El texto, conocido vulgarmente como Estils d'Arnau d'Erill, lleva por título Stili sive ritus curiarum. ${ }^{43}$ Sin embargo, el preámbulo indica que contiene consuetudines et stilos, dos elementos que no se identifican plenamente. Las costumbres propiamente dichas eran aquellas normas creadas

\footnotetext{
${ }^{39}$ ARM, Suplicacions 1, f. 195.

${ }^{40}$ T. de Montagut Estragués, "Comunidades locales en Cataluña y su derecho medieval”, Vasconia. 36, 2009 , p. 11.

${ }^{41}$ L. Mayali, "La coutume dans la société romaniste", Recueils de la Société Jean Bodin pour l'histoire comparative des institutions, LII, Bruselas, 1990, p. 24.

${ }^{42}$ J. Egea Fernández y J. M. Gay Escoda, "Eficàcia de les normes a la tradició jurídica catalana des de la baixa edat mitjana fins al Decret de Nova Planta", Revista Jurídica de Cataluña, LXXVIII, 3, 1979, p. 510 .

${ }^{43}$ ARM, Llibre d'en Sant Pere, ff. 31-31v. Llibre de Jurisdiccions i Stils, ff. 99-101v. Códice 90 A, ff. $32 \mathrm{v}-34 \mathrm{v}$. A. Moll, Ordinacions i sumari dels privilegis consuetuts i bons usos del regne de Mallorca, Mallorca, 1663, pp. 121-127.
} 
a través de la reiteración de actos y que se practicaban por la generalidad del pueblo. En cambio, con el término 'estilo' se designaban aquellas costumbres que practicaban los tribunales de justicia en el orden de proceder en las causas. Este es el elemento al que se puede designar como rito de las curias (ritus curiarum).

El preámbulo de la colección afirma que la redacción se llevó a cabo tras consultar con los Jurados del Reino y su Consejo plenario. El gobernador Erill dispuso que en el futuro los estilos y costumbres sólo serían vinculantes en cuanto se probase su uso y fuesen autorizados por escrito por los gobernadores o lugartenientes. Así mismo ordenó que en adelante, si se alegaba en un pleito una costumbre o estilo no redactado, se debería comparecer ante el gobernador para que, junto con su Consejo, determinase si podía ser admitido o no. En caso de que éste lo considerase admisible, se debía asignar un plazo de ocho días para que quien lo alegase pudiese probarlo. Si quedaba admitido una vez practicada la prueba, debía redactarse por escrito y ser observado en adelante como los restantes.

Mediante este sistema se pretendió que aquellas costumbres que el gobernador y su Consejo considerasen inadecuadas, perdieran su carácter normativo, sin que ni siquiera se llegara a practicar la prueba. La colección oficial se concibió, por tanto, como un importante filtro para la admisión de determinadas costumbres. Aunque no se señaló el criterio en función del cual se determinaría su admisibilidad, podemos suponer que con esta regla se quiso introducir un criterio de justicia o racionalidad, entendidas en un sentido amplio, tal y como lo exigía el derecho canónico. De todas formas, no hemos documentado ningún caso en el que se prohibiese la práctica de la prueba de la costumbre.

Por otra parte, con esta colección se quiso fijar a priori el Derecho consuetudinario, para evitar las dilaciones que suponía una abusiva negación del carácter vinculante de los usos previamente admitidos en juicio contradictorio, por la parte que se veía perjudicada por ellos. En efecto, la discusión entre partes acerca de la existencia de una determinada costumbre era uno de los elementos esenciales en determinados procesos y podía llegar a suponer una enorme demora en su resolución, como se puede comprobar en muchos de los autos que se han conservado. Esa realidad fue invocada en 1228 por Guillem Botet como justificación para la redacción de las Costums de Lleida con estas conocidas y significativas palabras: ut aufferretur occasio malignandi qui quando erat pro eis consuetudo et esse consuetudinem affirmabant. Si contra eos in consimili casu allegabatur non esse consuetudinem asserebant. Unde processus causarum probacio consuetudinis retardabat et litigantes inde dispendia gravia sentiebant. ${ }^{44}$

La redacción original de la colección de Erill quedó integrada por 29 capítulos, que recogieron algunas costumbres en materia civil y, sobre todo, un conjunto de usos judiciales. Posteriormente fue ampliada con seis nuevos estilos y costumbres

\footnotetext{
${ }^{44}$ P. Loscertales de Valdeavellano, Costumbres de Lérida, Barcelona, 1946, p. 17.
} 
que fueron aprobados, tras seguir el procedimiento previsto, por mandato de los lugartenientes Felip de Boïl el 28 de febrero de 1345, ${ }^{45}$ Francesc Sagarriga el 22 de marzo de 1378, ${ }^{46}$ y Joan Aymeric, el 6 de abril de $1430 .{ }^{47}$ En agosto de 1432 se redujo a escrito un estilo judicial según el cual en caso de discordancia entre el asesor o juez delegado y los prohombres, con respecto a la resolución de un litigio, debe prevalecer la opinión de éstos. Dicho estilo fue probado ante el gobernador y su asesor mediante el testimonio de diversos abogados y notarios, que manifestaron que se había aplicado durante más de treinta años, y finalmente el gobernador decretó que fuese observado obligatoriamente en el futuro. ${ }^{48}$ El 17 de septiembre de 1434 se añadió un nuevo estilo decretado por Joan de Far, lugarteniente del gobernador Berenguer Doms, sobre la facultad de los rectores y vicarios de la parroquias en las que no residiesen notarios para tomar contratos y firmas como subrogados de aquéllos. ${ }^{49}$ El último de los usos y estilos cuya vigencia fue probada ante la curia del gobernador, y que se incluyó en algunas colecciones, se refiere al salario de los jurisperitos y notarios que intervenían como prohombres en la formación de las sentencias. El 11 de marzo de 1437 el lugarteniente de gobernador, Bernat de Llupià, ordenó que se redactase por escrito y que se tuviese por uso y costumbre en cualquiera de las curias de Mallorca. ${ }^{50}$

Sólo un año después de la formación del núcleo inicial de la colección, hemos documentado sendos pleitos en los que una de las partes pretende probar la existencia de una costumbre (intendit probare quod usus, stilus, consuetudo et observantia Maioricarum existit) sobre la que apoya sus pretensiones. En el primero, el estilo alegado es una regla procesal acerca de las sentencias interlocutorias. En el segundo, un aspecto sobre el régimen jurídico de los censales. En este último caso, la parte interesada presentó numerosos testigos, todos ellos notarios o causídicos, y el gobernador designó al jurisperito Arnau Mendoni juez delegado para resolver tanto sobre la existencia del estilo como sobre la cuestión principal. ${ }^{51}$ Aunque no nos consta si las costumbres alegadas se consideraron probadas o no, lo cierto es que no fueron añadidas a la colección.

El estrecho parentesco entre las costumbres y estilos mallorquines y menorquines motivó que se formase en Menorca una colección en la que se recogieron los estilos de la redacción de Erill y el de Felip de Boïl de 1345. La copia se llevó a cabo bajo el gobierno de Gil de Lozano, durante el reinado de Pedro IV. ${ }^{52}$ Con posterioridad se

\footnotetext{
${ }^{45}$ ARM, Llibre de Jurisdiccions i Stils, f. 101v. A. Moll, Ordinacions..., pp. 127-128.

${ }^{46}$ ARM, Llibre de Jurisdiccions $i$ stils, f. 60v. A. Moll, Ordinacions..., pp. 129-130.

${ }^{47}$ ARM, Llibre de Jurisdiccions i stils, f. 120v. A. Moll, Ordinacions..., pp. 133-134.

${ }^{48}$ ARM, Suplicacions 35, ff. 1-3v. Pub. A. Planas Rosselló, "La participación popular...”, pp. 177-180.

${ }^{49}$ ARM, Llibre de Jurisdiccions $i$ stils, f. 137. A. Moll, Ordinacions..., pp. 131-132.

${ }^{50}$ ARM, Códice 24, ff. 115v-116v. A. Moll, Ordinacions..., pp. 134-136.

${ }^{51}$ ARM, AH 441, f. 56 y ff. 80-86.

${ }^{52}$ No hemos podido datar esta copia. El único manuscrito existente da como fecha el año milessimo trecentesimo quarto, que evidentemente es errónea. Gil de Lozano fue portantveus de gobernador entre 1358 y 1361, y gobernador de la isla entre 1361 y 1370.
} 
le añadieron algunos textos que no constituían propiamente costumbres o estilos; entre ellos, varios modelos de pregones de la curia del gobernador de la isla. ${ }^{53}$

La colección iniciada por Erill no supuso la fosilización de las costumbres y estilos o usos judiciales, que en ningún caso quedaron reducidos a los estrechos márgenes de aquel texto. Otras muchas instituciones consuetudinarias siguieron siendo practicadas cotidianamente sin haber sido objeto de formulación escrita. Algunas de ellas afloraron mucho más tarde en los manuales de notaría, en algunas compilaciones privadas o, en caso de que resultasen en algún momento controvertidas, a través de las sentencias de los tribunales. Por ejemplo, los derechos consuetudinarios del cónyuge viudo, a pesar de que nos consta que algunos de ellos se remontaban como mínimo al siglo XIV, no se redactaron por escrito hasta que en 1622 los doctores Canet, Mesquida y Zaforteza quisieron fijarlos en una ordinació nova de su proyecto de recopilación. ${ }^{54}$ Así mismo muchas costumbres que la práctica mantenía vivas prosiguieron su existencia silenciosa, con plena validez y eficacia, sin que se llegasen a redactar en momento alguno.

Por otra parte, las viejas costumbres medievales no dejaron de evolucionar a lo largo del tiempo. Por ejemplo, los citados doctores afirmaban en su proyecto de 1622 que desde poco tiempo atrás la costumbre de asignar a la viuda la llamada part de cambra -la mitad de las ropas de lino y lana del ajuar doméstico- se había sustituido por el cuatro por ciento de la dote constituida, que quedaba propio y libre de la mujer. Así lo podemos comprobar, efectivamente, en los instrumentos notariales de aumento de dote de esa época. ${ }^{55}$

\section{La costumbre en el ámbito penal}

En los apartados anteriores nos hemos referido casi exclusivamente a las costumbres civiles y los usos procesales, los dos elementos que aparecen constantemente en las fuentes y que fueron objeto de la redacción oficial de Erill. Pero la costumbre también manifestó cierta capacidad normativa en el ámbito penal, al que debemos dedicar una consideración aparte. La carta de población de 1230, en contraste con su silencio respecto a las fuentes del derecho, dispuso que en los pleitos sobre injurias, daños o heridas se aplicasen los Usatges de Barcelona, ${ }^{56}$ aunque el texto catalán re-

\footnotetext{
${ }^{53}$ ARM, AH 4.812.

${ }^{54}$ A. Planas Rosselló, Recopilación..., p. 201.

${ }^{55}$ A. Planas Rosselló, Recopilación..., p. 201. Según el formulario notarial de Antoni Moll (1714), el marido incluye las palabras "et eandem hujus regni insequendo consuetudinem approbatam, acolligo vos in medietate pannorum camara nostra, qua quidem pannorum medietas computatur ad rationem quatuor pro centenario dicta dotis constituta" (L. Zaforteza; A. Mut; M. Oliver, Tratados de notaría..., pp. 452, 454, 713, 715).

${ }^{56}$ In causis iniuriarum, dampnis vulneribus illatis, procedatur secundum Usaticum Barchinone (ARM, Llibre de privilegis dels Reis, f. 16).
} 
sultaba notoriamente insuficiente para responder a todas las cuestiones que planteaba esta rama del derecho. Por ello, la costumbre aportada por los repobladores y, sobre todo, los usos judiciales, intervinieron activamente en su configuración. Sin embargo, las reglas creadas o consolidadas de esta forma resultan de difícil conocimiento, pues sólo se manifiestan expresamente en la documentación en algunas ocasiones en las que se aduce que han sido conculcadas.

En todo caso, para valorar el papel de la costumbre penal en Mallorca es preciso atender a dos elementos que contribuyeron a perfilarlo: la posibilidad de pacificación privada de los delitos y el principio de arbitrio judicial.

La carta de población permitió que los particulares pudieran pacificar los delitos antes de hacer instancia a la curia. ${ }^{57}$ Como consecuencia de esta institución, el delito se presenta como una cuestión entre particulares, de forma que si la curia no es instada por la parte ofendida, son las partes quienes pueden restablecer la paz, con la mediación de los prohombres, según su propio criterio. La documentación no ha dejado huella de las vías utilizadas para conseguir tales pacificaciones, que debieron consistir principalmente en enmiendas económicas no tarifadas, aunque cabe pensar que se acudió también a otras formas de resarcimiento. En 1300 Jaime II prohibió la práctica de tales pacificaciones cuando se tratase de delitos graves, para evitar que quedasen impunes. ${ }^{58}$ Aunque esta disposición fue derogada por Sancho I en 1311, la intervención de oficio de los tribunales reales para el ejercicio de la vindicta pública fue en constante aumento. Sin embargo, como reverso de la paz privada, se mantuvo en Mallorca la venganza privada, una institución legitimada por la costumbre, a pesar de ser desconocida cuando no proscrita por la legislación. A diferencia de otros reinos de la Corona de Aragón, en los que la institución estuvo sujeta a una profusa regulación legal, la venganza sólo se asoma a los textos normativos mallorquines en momentos de gran inestabilidad social, cuando el poder público se aviene a admitir esa realidad, a fin de limitar sus efectos. Por ejemplo, en 1425 el lugarteniente de gobernador Ramon Zaforteza dispuso mediante edicto que quienes pretendiesen ofender por obra a alguna persona, deberían desafiarla mediante escritura autorizada por un notario público, y que en caso de que ejecutasen la ofensa sin previo desafío o sin haber transcurrido dos días desde la fecha de éste, serían castigados a pena de muerte y confiscación de bienes, como los reos de delito de lesa majestad. ${ }^{59}$

En la medida en que la jurisdicción real asumió el ejercicio de la vindicta pública, hizo uso del principio de arbitrio judicial, una creación de la doctrina del Ius Com-

\footnotetext{
${ }^{57}$ Omnia malefacta que fuerint inter habitatores civitatis possint probi homines pacificare et diffinire antequam sit clamor vel firmamentum ad curiam factum (ARM, Llibre de privilegis dels Reis, f. 15v).

${ }^{58}$ Ne maleficia remaneant impunita, quod in gravibus criminibus curia nostra vindictam nichilominus assumere valeat et penam imponere malefactoribus, non obstantibus diffinicione et pace factis per probos homines inter partes (ARM, Llibre de Jurisdiccions i Stils, f. 40).

${ }^{59}$ A. Planas Rosselló, "Derecho, venganza y duelo en la Mallorca medieval y moderna", MRAMEGH, 9,1999, pp. 7-24.
} 
mune, característica de la justicia penal medieval y moderna ${ }^{60}$ que supuso una importante limitación a la configuración de la costumbre como fuente. La posibilidad de que los jueces impusieran las penas que considerasen adecuadas a cada delito en función de las particulares circunstancias que concurrieran en cada caso, redujo los márgenes de un derecho penal consuetudinario. Sin embargo, la costumbre penal constituyó a su vez un límite al arbitrio de los jueces. ${ }^{61}$ La abstención o práctica de no hacer por parte de éstos, generó unas costumbres o usos judiciales negativos a los que el reino se aferró como auténticos privilegios penales de los naturales. Por ello, en aquellas ocasiones en que los tribunales reales impusieron penas o realizaron otras prácticas penales inusitadas, las autoridades regnícolas actuaron con gran celo para evitar su consolidación. Así, el 11 de agosto de 1430 el rey Alfonso V, tras ser legítimamente probada, confirmó un antigua costumbre - a tanto tempore citra hactenus observata fuisse, quod memoria hominum in contrarium non existit- que prohibía someter a la pena de azotes a los mallorquines libres, y ordenó al gobernador que en el futuro se abstuviese de practicar esta novedad o cualquier otra contra consuetudines et usus dicti regni ${ }^{62}$ Más llamativa es una exposición presentada por los jurados al lugarteniente general en 1483, instándole a respetar una antigua costumbre (longa consuetut per longitut de temps que memòria de hòmens no és en contrari) que permitía a los habitantes de la villa de Andratx degollar a cualquier esclavo musulmán que fuera hallado a menos de media legua del mar, y colocar su cabeza en la punta de una lanza en la plaza del pueblo, sin incurrir en responsabilidad criminal por ello. ${ }^{63}$

En la época de los Austrias los jurados del reino tuvieron que estar especialmente atentos a las conculcaciones de los privilegios creados mediante costumbres negativas. Por ejemplo, en 1578 se dirigieron a Felipe II para exponer sus quejas por ciertas prácticas penales introducidas por la recién creada Real Audiencia, de lo que dits habitadors pretenen greuge, per ésser contra bonos mores et usum inconcusse observatum, y consiguieron que el monarca, acogiendo su petición, dispusiese el restablecimiento de los usos antiguos. ${ }^{64}$ Sin embargo, en las décadas siguientes el nuevo tribunal, que rechazó motivar sus sentencias, hizo un amplio uso de su arbitrio judicial para reprimir con dureza el creciente bandolerismo, vulnerando con mucha frecuencia los viejos privilegios consuetudinarios medievales. ${ }^{65}$

\footnotetext{
${ }^{60}$ B. Schnapper, "Les peines arbitraires du XIII ${ }^{\mathrm{e}}$ au XVIII ${ }^{\mathrm{e}}$ siècle", Tijdschrift voor rechtgeschiedenis, 41, 1973, pp. 237-277 y 42, 1974, pp. 81-112.

${ }^{61}$ J.-M. Carbasse, Histoire du droit pénal et de la justice criminelle, Paris, 2000, pp. 211-212. Para el caso concreto de Montpellier vid. M. Lesne-Ferret, "Arbitraire des peines et droit coutumier dans le midi de la France: le cas de Montpellier”, Studi di Storia del diritto, I, Milán, 1996, pp. 27-45.

${ }^{62}$ ARM, Llibre d'en Sant Pere, f. 147v; LR 55, f. 145. Pub. A. Planas Rosselló, El Derecho penal histórico de Mallorca (siglos XIII-XVIII), Palma, 2001, pp. 183-184.

${ }^{63}$ E. Fajarnés, "Las cabezas de los degollados", BSAL, VI, 1895-1896, pp. 147-148.

${ }^{64}$ A. Planas Rosselló, El proceso penal en el reino de Mallorca, Palma, 1998, pp. 168-170.

${ }^{65}$ A. Planas Rosselló, La Real Audiencia de Mallorca en la época de los Austrias (1571-1715), Barcelona, 2010, pp. 266-273.
} 


\section{Recapitulación}

La costumbre constituyó el elemento básico en la inicial configuración del derecho de Mallorca. A pesar de la disparidad de origen de los repobladores del reino, las distintas instituciones consuetudinarias aportadas por ellos convivieron en un primer momento y se fueron consolidando, modificando o desapareciendo - por sí mismas o a través de disposiciones legislativas- según su nivel de adaptación a las necesidades sociales. La difusión del Ius Commune contribuyó asimismo a encauzar algunas instituciones consuetudinarias que -como el esponsalicio o la tenencia de tierras en régimen de acapte- se fueron modulando para adaptarse al régimen de las instituciones romanas con las que guardaban mayores analogías (como la dote o la enfiteusis en los ejemplos citados). La recepción oficial del derecho común supuso un freno a la vitalidad de la costumbre como fuente, pues quedó sujeta a los rigurosos requisitos exigidos por la doctrina romanista o canónica. Tras la conquista del reino por Pedro IV de Aragón, el gobernador Arnau d'Erill pretendió limitar sus efectos mediante la redacción de una colección oficial de las costumbres y usos judiciales que resultasen probados ante su curia. Por una parte pretendía excluir las costumbres que se considerasen inadmisibles y por otra que en el futuro no fuese necesario someter a prueba aquéllas que ya hubieran sido redactadas, a fin de afianzar la seguridad jurídica y agilizar el proceso. A pesar de ello, la costumbre no escrita mantuvo su carácter de fuente del derecho. Muchos viejos usos que la práctica mantenía vivos prosiguieron su existencia silenciosa sin que se llegasen a redactar en momento alguno, e incluso aparecieron nuevos usos por la adaptación de aquéllos a las nuevas circunstancias. A partir de estas premisas, las antiguas costumbres mallorquinas en materia civil han prolongado su eficacia hasta la época actual con una doble función: como fuente del derecho civil propio en defecto de ley, o como parte de la tradición jurídica balear que, de acuerdo con la compilación vigente, se constituye en elemento integrador del sistema jurídico. ${ }^{66}$

\footnotetext{
${ }^{66}$ A. Martínez Cañellas, "Sobre el derecho consuetudinario balear como fuente y como tradición jurídica", BAJLIB, 10, 2009, pp. 31-84.
} 